Nicholas W. Lukacs

Kim K. Tekkanat

\section{Role of chemokines in asthmatic airway inflammation}

Authors' addresses

Nicholas W. Lukacs ${ }^{1}$, Kim K. Tekkanat²,

${ }^{1}$ University of Michigan Medical School, Department of Pathology, Ann Arbor, Michigan, USA.

${ }^{2}$ University of Michigan Medical School, Department of Internal Medicine, Division of Pediatrics, Ann Arbor, Michigan, USA.

Correspondence to:

Nicholas Lukacs

University of Michigan Medical School

Department of Pathology

1301 Catherine

Ann Arbor MI 48109-0602

USA

Fax: 17347642397

e-mail: nlukacs@umich.edu
Immunological Reviews 2000

Vol. 177: 21-30

Printed in Denmark. All rights reserved

Copyright (C) Munksgaard 2000

Immunological Reviews ISSN 0105-2896

\begin{abstract}
Summary: The incidence of asthma worldwide has increased significantly over the past two decades, especially in young children and in inner cities. Although there are several contributing factors that promote severe asthmatic responses, uncontrolled inflammation leads to the most severe consequences. Chemokines are an interesting target for decreasing the inflammatory response and therefore altering the pathogenesis of asthma reactivity in the lungs. However, it has become clear that there are a number of chemokines that play important roles in various aspects of asthmatic inflammation and reactivity. Identifying the functions each of these chemokines plays during the responses will be imperative to properly target different phases of the asthmatic condition. This review will outline what is known of the role of various chemokines that are produced during asthmatic responses and speculate on the appropriateness of targeting these mediators for therapy.
\end{abstract}

\section{Chemokines in clinical asthmatic responses}

Over the past several years a family of chemotactic cytokines has been identified that appears to have specificity for the type of leukocytes that are recruited to the site of inflammation $(1-5)$. Chemokines have been primarily divided into two main subfamilies based upon their sequence homology and the position of the first two cysteine residues, $\mathrm{C}-\mathrm{X}-\mathrm{C}(\alpha)$ and $\mathrm{C}-\mathrm{C}(\beta)$. This group of chemoattractants has grown to include more than 40 different molecules. In vitro characterization would suggest that most of these chemokines have redundant or similar functions with other known chemokines. In addition to the chemokines, there are also numerous receptors that have been identified. The realization of the role of chemokines for mediating leukocyte accumulation and activation led investigators to begin to examine which chemokines are expressed at significant levels during human asthmatic disease. Bronchoalveolar lavage and sputum samples from asthmatics became the easiest method of determining chemokine levels in patient populations. Several studies have now identified that both $\mathrm{C}-\mathrm{X}-\mathrm{C}$ and C-C family chemokines are upregulated after allergen challenge, and the levels relate directly to the intensity of the airway reactivity responses $(6-11)$. The airway epithelial cells and 
alveolar macrophages produce significant levels of chemokines that can have an immediate impact on the environment of the airway and surrounding lung tissue. Initial investigations in human populations have centered on eosinophil-specific chemokines, as the eosinophil appears to be an important cell population in the pathology of asthma. Over the past several years, a number of chemokines, such as interleukin (IL)-8, RANTES, monocyte chemoattractant protein (MCP)-3 and MCP-4, have been identified that induce eosinophil recruitment (12-16). The one important question, however, is whether all of the chemokines function as eosinophil chemoattractants or whether a specific chemokine mediates the bulk of the chemotactic activity and can be targeted for therapy. Eotaxin is one of the only chemokines that appears to function primarily for eosinophil chemotaxis. In human asthma, eotaxin is produced at high levels and localized to the airway epithelium $(17,18)$. This concentrated expression may preferentially target eosinophils to the epithelium and induce degranulation leading to release of epithelium-damaging proteins. In addition, to recruiting and activating eosinophils, eotaxin can affect other cell populations. Basophils degranulate in the presence of eotaxin, while Th2-type cells can migrate toward eotaxin (19-21). Thus, eotaxin may be a primary target for therapeutic intervention. However, other chemokines and their receptors will also need to be examined, as there seems to be a great deal of functional overlap throughout the chemokine family.

\section{Chemokines and early phase asthmatic responses}

One of the first series of cells activated during allergen-induced airway reactivity and asthma are mast cells and basophils (22, 23). These cell populations are closely associated with the severity of the asthmatic reactivity and can be immediately activated for release of preformed mediators by IgE-induced degranulation. However, the chronic activation of these cells has recently been recognized and constitutes a possible component of the late phase asthmatic response (24). There are a number of chemokines that can induce chemotaxis of basophils and mast cells (25-28). Initial studies have shown that the CC chemokines MCP-1, 2 and 3, RANTES, macrophage inflammatory protein (MIP)-1 $\alpha$ and eotaxin can all induce recruitment of basophils and mast cells. In addition to the recruitment of these cells, it is now evident that particular chemokines can also serve as activating factors that induce basophil and mast cell degranulation. In particular, MCP- 1 and RANTES are able to induce significant histamine release from basophils. In fact, MCP-1 can induce nearly as much histamine release as IgEmediated stimulation. This becomes important for chronic activation of these cells as the temporal production of MCP-1 indicates that it is produced at later phases of the allergic response, after allergen has been cleared, and therefore likely promotes continued cellular activation and mediator release without the presence of antigen $(10,29-31)$. Interestingly, eotaxin can potentiate basophil activation for the production of IL-4, and therefore, enhance the Th2 type environment created in the lung during allergic responses (32). This pathway of activation would allow prolonged activation and continuous degranulation of basophils during the allergen-induced responses.

Other studies have indicated that MCP-1 is also a potent activation factor for mast cells both in vitro and in vivo $(30,33)$. Subcutaneous injection of MCP-1 causes a dose-dependent accumulation of mast cells in the skin of rats (34) leading to local edema and leukocyte accumulation. The neutralization of MCP-1 during allergen-induced airway hyper-reactivity responses can significantly alter the adverse pathophysiologic events (30). The use of $\mathrm{CCR}^{-/-}$mice during the allergeninduced responses further confirmed the relevance of this ligand-receptor activation pathway for the induction of airway hyper-reactivity. Interestingly, intratracheal injection of MCP-1 into the airways of mice directly induces mast cell degranulation and long-term airway hyper-reactivity. The latter study demonstrated that MCP-1 induced the activation and release into the airway of leukotriene C4 (LTC4), an arachidonic acid metabolite with the ability to induce airway hyper-reactivity. The fact that MCP-1 can induce LTC4-mediated pathways makes an important link between chemokine and arachidonic acid metabolite biology $(30,35)$. Thus, one potential target for alleviating certain phases of asthmatic inflammation linked to mast cell activation is MCP- 1 and its receptor CCR2. Overall, chemokine-mediated exacerbation of chronic asthmatic disease may perpetuate activation of basophils and mast cell populations leading to a more severe outcome.

\section{Recruitment and activation of leukocyte subsets during allergic responses}

\section{Neutrophils}

The inflammation induced during allergic airway inflammation is mediated by the coordination of several immune specific activation events. The first leukocyte that appears to enter a site of allergic inflammation is the neutrophil (11). The activation and degranulation of local mast cell populations is an immediate response in the airway, mediated both by antigen-specific, surface-bound IgE and by cytokine-induced activation pathways. The relevance of neutrophils to airway hyper-reactivity 
and subsequent late phase reactions and airway damage in atopic asthma has traditionally been a controversial topic. However, results collected over recent years have provided data that suggest that neutrophils, at the very least, have a role in inducing airway damage leading to lung dysfunction (36-39). The recruitment of neutrophils to the airway during allergic responses has been well documented. Neutrophils are a source of several inflammatory mediators as well as destructive proteases capable of damaging surrounding tissue in the lung (40). The family of chemokines containing C-×-C-ELR, which includes IL-8, epithelial cell-derived and neutrophil-activating 78-amino acid peptide (ENA-78) and growth-related oncogene product (GRO) $\alpha, \beta$ and $\gamma$, is primarily chemotactic for neutrophils. Several pieces of evidence have correlated $\mathrm{C}-\mathrm{X}-\mathrm{C}$ chemokines and neutrophils with the onset and maintenance of asthmatic inflammation. In particular, high levels of IL-8 have been observed in bronchoalveolar lavage fluid samples from asthmatics after allergen challenge $(11,41)$. In sudden onset fatal asthma, neutrophils were the predominant cell population found in the airspace with few eosinophils (42-44). To support the concept that neutrophils can initiate asthmatic responses, supernatants from degranulated neutrophils incubated with human bronchus increase the responsiveness to histamine (45). A number of studies have now begun to correlate the presence of neutrophils in asthmatics with severe chronic disease and peribronchial fibrosis (46). These latter issues have begun to take center stage in asthma as the more severe responses that are observed seem to relate to end-stage fibrosis and thickening of the large airways.

A number of studies have demonstrated the relationship of neutrophil accumulation, $\mathrm{C}-\mathrm{X}-\mathrm{C}$ chemokines and airway responsiveness. Studies examining the role of ozone in asthmatics have demonstrated that there is a significant increase in IL-8, sputum neutrophilia and an associated increase in airway reactivity (47-51). In animal models, ozone can increase airway hyper-reactivity responses that are correlated directly to the intensity of neutrophil infiltration observed. Additional animal studies have begun to further define a role for $\mathrm{C}-\times-\mathrm{C}$ chemokines and neutrophil influx during allergen-induced airway hyper-reactivity. Specifically, ENA-78, a molecule with similar function to IL-8, is found premade in mast cells and appears to be quickly released upon antigen stimulation in vitro and in vivo (52). The neutralization of this chemokine during allergen-specific responses in mice significantly reduces the neutrophil influx. In studies with guinea pigs, instillation of IL8 can significantly induce granulocyte accumulation and airway reactivity responses (53). Thus, the $\mathrm{C}-\mathrm{X}-\mathrm{C}$ chemokines may have a prominent role in the late phase responses for recruitment and activation of neutrophils, leading to airway damage and physiologic dysfunction.

\section{Eosinophils}

There is no doubt that the overwhelming number of asthmatics that present with moderate to severe chronic disease are characterized by significant eosinophil accumulation and activation within the airway $(38,54,55)$. Like neutrophils, eosinophils contain a number of products that when released directly impact on the function of the airways, either by damaging the structural cells or influencing other physiologic regulators. Determining the mechanisms of activation and recruitment of eosinophils in the airway is a focus of most researchers examining asthmatic disease. Although IL- 8 can be shown to induce eosinophil accumulation, its relative efficacy compared to a number of $\mathrm{C}-\mathrm{C}$ chemokines may not be as vital. Over the past several years a number of CC chemokines that bind to CCR3, the major receptor that is expressed on the circulating eosinophil population, have been shown to induce chemotaxis and activation of eosinophils $(15,56-60)$. These chemokines include RANTES, MCP-3, MCP-4, eotaxin and eotaxin-2. Of these chemokines only eotaxin and eotaxin-2 bind specifically to CCR3 and not to other receptors. Furthermore, eotaxin appears to be the most potent chemokine for movement of these cells into tissue. However, additional studies have now demonstrated that other non-CCR3-binding chemokines can cause the migration and activation of eosinophils. Some of the earliest studies using peripheral human eosinophils indicated that MIP- $1 \alpha$, a CCR 1 ligand, could also induce chemotaxis of eosinophils (61). This observation has been reflected in murine systems that have demonstrated a function for MIP-1 a as an eosinophil recruitment factor both in vitro and in vivo (62-64). More recently, MDC, a CCR4 ligand, has also been identified as an eosinophil recruitment factor but does not depend upon CCR4 or CCR3 binding $(65,66)$. Therefore, MDC likely utilizes a different receptor than other known eosinophil chemotactic factors. Studies that have been performed in our laboratory have demonstrated that a complicated picture of eosinophil recruitment and activation may be emerging. Although peripheral eosinophils from mice follow what has previously been described, when elicited eosinophils are used the pattern of chemokine utilization changes drastically (Table 1). In peripheral eosinophils, only CCR 1 and CCR3 ligands induce chemotaxis. However, when eosinophils are elicited to the peritoneum of sensitized mice, the isolated eosinophils from these lesions migrate to ligands specific for additional receptors. We have now shown that the CCR5 and CCR8 ligands MIP-1 $\beta$ and thymus-derived chemotactic agent 
Table 1. CC chemokine receptor function on eosinophils

\begin{tabular}{|c|c|c|c|c|}
\hline \multirow[b]{2}{*}{ Receptor (chemokine) } & \multicolumn{4}{|c|}{ Chemotaxis/mRNA expression } \\
\hline & Control & $\mathrm{IL}-4$ & TNF & Ca flux \\
\hline CCR1 (MIP-1a) & $++/++$ & $-1+$ & $+++/+++$ & ++ \\
\hline CCR2 (MCP-1) & $-1-$ & $-1-$ & $-1-$ & - \\
\hline CCR3 (eotaxin) & $+++/+$ & $+++/++$ & $+++/+++$ & +++ \\
\hline CCR4 (TARC) & $-1-$ & $-1-$ & $-1-$ & - \\
\hline CCR5 (MIP-1 $\beta)$ & $-1-$ & $++/++$ & $++/++$ & - \\
\hline CCR8 (TCA3) & $-1-$ & $+/++$ & $+/++$ & - \\
\hline
\end{tabular}

aDetermined by desensitization assays

(TCA) 3 can induce elicited eosinophils to migrate in chemotactic assays. Additional studies indicated that IL-4 and tumor necrosis factor (TNF), but not interferon (IFN), can upregulate the expression and function of CCR5 and CCR8 on eosinophils. Thus, once properly activated, such as in asthmatic patients, additional chemokines can affect the movement and activation of eosinophils. These concepts will be important for understanding the biology of eosinophil migration and activation in allergic tissues.

\section{Lymphocytes}

The migration of lymphocytes into tissues appears to be dependent upon the expression of specific chemokines during the progression of inflammatory disease. Investigators have begun to define the association of certain chemokine profiles with particular types or phases of immune responses. The preferential expression of certain chemokines during immune responses likely dictates their function. For example, the CC chemokine family members RANTES, MIP- $1 \alpha$ and MIP- $1 \beta$ are induced by IFN and TNF but regulated by IL-4, and appear to be closely associated with Th1-type responses (67-70). Likewise, the production of $\mathrm{CxCR} 3$ ligands (IFN- $\gamma$-inducible protein-10 (IP-10), monokine induced by IFN- $\gamma$ (MIG) and IFNinducible T-cell $\alpha$ chemoattractant (ITAC)) are specifically activated by IFN and may have critical roles in enhancing Th1-type lymphocyte recruitment and activation. Along with the preferential expression of chemokines during Th1-type responses, there is also the preferential expression of the associated chemokine receptors on Th1-type lymphocytes $(21,71,72)$. A number of studies have shown that CCR 1 and CCR5 (which bind RANTES and MIP-1 $\alpha$ ) as well as CxCR3 (which binds IP10, MIG and ITAC) on Th1-type lymphocytes are favorably expressed. Thus, the chemokine expression during a Th1-type response correlates directly with the specificity of the chemokine receptors that are expressed on Th1-type lymphocytes.
As there are chemokines associated with Th1-type responses, there also appear to be certain chemokines that are closely associated with Th2-type responses. An impressive body of work has accumulated on CC chemokines and the expression of particular members of this family that are specifically activated by IL-4 and IL-13. The CC chemokines that are preferentially upregulated by Th2-type cytokines include MCP-1, eotaxin, TCA3, thymus and activation-regulated chemokine (TARC) and macrophage-derived chemokine (MDC) (73-76). Interestingly, these IL-4 and IL-13-induced chemokines appear to bind to a single chemokine receptor, which is unusual among chemokine family members, which normally have a promiscuous binding pattern to multiple chemokine receptors (77). Thus, the Th2 activation pathway, which has been associated with allergen-induced airway hyperreactivity, induces preferential chemokine production that is associated with allergic cell recruitment. This area will be of particular interest since studies have previously identified that these Th2-associated chemokines play significant roles in allergen-induced airway inflammation and airway hyper-reactivity $(29,65,78-81)$. Analysis of in vitro derived Th2-type cells indicates preferential expression of CCR3 (eotaxin), CCR4 (MDC, TARC) and CCR8 (TCA3) $(21,71,72,82)$. This receptor expression pattern correlates well with the type of chemokines that are induced by Th2-type responses discussed above. Importantly, a recent study demonstrated that both CCR3 and CCR4 are utilized for sequential movement of Th2-type cells into allergen-challenged lungs (83). These results indicate that the expression of multiple receptors by lymphocytes functions to allow sequential migration of cells throughout chronic asthma-like responses. Verification of these specific responses will come from preclinical animal models and examination of receptor expression on circulating and infiltrating lymphocyte populations.

\section{Regulation of cellular recruitment by airway epithelial cell-derived chemokines}

The airway epithelial cells are one of the first lines of defense against invasion by infectious agents, primarily providing a barrier role in the lung (84-87). Over the past several years, airway epithelial cells have been identified as a source of a number of chemokines that may impact on the immune responses generated within the lung. The activation of chemokines in epithelial cells can dictate the type of cells that migrate in and therefore are responsible for creating a specific inflammatory environment in the lung that determines how the lung reacts to antigenic stimuli and disease. The activation of the epithelial 
cells by TNF or IFN leads to the production of the chemokines IP-10, ITAC and RANTES which are associated with Th1-type responses (69). In contrast, the activation of these structural cells with IL-4 or IL-13 will lead to the production of chemokines such as eotaxin, MCP-3 and 4 that are related to allergictype responses and can preferentially recruit Th2 cells and eosinophils $(15,59,74,88-90)$. Thus, the cytokine environment initiated by the structural cells of the airway can determine the type of cells and responses that are generated within the lung.

It has been recognized that an additional role for the airway epithelial cells may be as a regulatory cell that modulates potentially harmful immune responses to innocuous antigens encountered in the lung. The constitutive production of IL-10, a potent cytokine suppressor factor, appears to regulate the resident cells of the airway to avoid local activation (91). Under normal circumstances the airway epithelial cells will want to protect themselves against damage to maintain lung function. It is only when an infectious or noxious agent is introduced into the lung that damages the airway epithelial cells that an immune response should occur. Thus, one could take the view that any cytokine that is made in a constitutive fashion by the airway epithelial cells may be produced in an effort to modulate the responses to environmental antigens. Eotaxin is one of the cytokines that is made constitutively by airway epithelium (18, 92). We have recently begun asking the question of whether eotaxin may normally have a protective role and only under atypical circumstances, such as allergy and peripheral eosinophilia, would promote an adverse response. Recent studies have identified the presence of CCR3 on neutrophils after cytokine stimulation, either IFN or TNF (93), suggesting a possible role during inflammation and cell-mediated immune responses. In studies using a neutrophil-dependent acute lung injury model, the neutralization of eotaxin in the airway significantly exacerbated the neutrophil influx and lung injury (P. A. Ward, personal communication). Likewise, the administration of exogenous eotaxin into the circulation of challenged mice significantly reduced neutrophil influx and acute lung damage. In additional studies in our labs, eotaxin could significantly reduce IL-8-mediated migration of neutrophils through an endothelial cell layer, suggesting that it may have a role in regulating the extravasation of neutrophils into a site of inflammation (S. Cheng, S. L. Kunkel, N. W. Lukacs, unpublished data). These latter ideas have been further examined in vivo using eotaxin $^{-/-}$mice, which were found to have significantly increased recruitment of neutrophils into acute inflammatory responses. Thus, a function of eotaxin may be to regulate the local homeostasis of the lung by controlling the influx of neutrophils that can directly damage the lung. In agreement with this concept, the Th2 cytokine-induced overexpression of eotaxin in allergic asthma would promote the influx of circulating eosinophils but not neutrophils. This mechanism may help to explain why asthmatics with a predominant Th2 phenotype, peripheral eosinophilia and significant levels of eotaxin have primarily an eosinophil infiltration with few neutrophils present. It is likely that other chemokines have similar regulatory functions depending upon the cell populations involved.

\section{Exacerbation of chemokines and asthmatic responses by viral infections}

A number of clinical studies have established that the most common stimulus that exacerbates asthmatic responses is viral infections of the airway. Common viral infections include rhinovirus, respiratory syncitial virus (RSV), adenovirus and influenza (94-97). A number of cytokine mediators have been shown to be induced by viral infections in both local macrophage populations and airway epithelial cells. In most of the cases the viruses provide a means for a general upregulation of inflammatory responses that leads to excerbated lung damage and dysfunction. However, certain chemokines appear to be specifically upregulated in cells during viral infections. Using isolated airway epithelial cells many of these viruses appear to be able to upregulate IL- 8 and RANTES (98-101). These chemokines may provide for a common defense pathway to begin the antiviral immune response through the recruitment of neutrophils (IL-8) and mononuclear cell populations (RANTES). Although their function in this regard remains unproven, clinical samples verify that these chemokines are upregulated (102). However, in an individual with a previous history of asthma, the accumulation and activation of these leukocyte populations can exacerbate the airway reactivity. A recent study has linked the level of chemokines induced by upper respiratory viral infections with the intensity of the asthmatic exacerbation as well as to eosinophil activation products in the airway (103). An important issue to discern is the fact that Th1-type antiviral responses induce several chemokines that augment the intensity of "Th2-type" inflammatory cell infiltration. For example, although RANTES has been identified as being primarily induced by acute and Th1-type mediators, it was one of the first and most potent eosinophil chemotactic factors identified that can facilitate eosinophil accumulation when injected in vivo $(104,105)$. Thus, asthmatic inflammation and exacerbation should not be considered only a Th2 cytokine-induced disease. This issue has recently been examined in experimental models where investigators co-transferred Th1 and Th2-type specific lymphocytes into a naïve mouse and 
Table 2. Chemokine receptor targets in asthma

\begin{tabular}{|c|c|c|}
\hline Receptor & Chemokine ligands & Function \\
\hline \multirow[t]{2}{*}{ CCR2 } & MCP-1 to 4 & Mast cell/basophil actvation \\
\hline & & T-lymphocyte recruitment \\
\hline \multirow[t]{2}{*}{ CCR3 } & Eotaxin, eotaxin-2 & Eosinophil chemotaxis/activation \\
\hline & MCP-3, MCP-4, RANTES & Th2-cell recruitment \\
\hline \multirow[t]{2}{*}{ CCR4 } & MDC, TARC & Th2-cell recruitment \\
\hline & & Dendritic cell recruitment \\
\hline \multirow[t]{2}{*}{ CCR8 } & $1-309$ & Th2-cell recruitment \\
\hline & & Smooth muscle cell contraction \\
\hline
\end{tabular}

found that the presence of Th1-type cells did not suppress development of pulmonary disease, but rather intensified the inflammation and exacerbated the lung pathophysiology (106, 107). The mechanism of direct viral induced chemokine expression is not completely clear in all cases. However, the work performed examining the induction of chemokines suggests that a primary pathway be via oxidative burst leading to $\mathrm{NF}_{\kappa} \beta$ activation induced by the infection of epithelial cells (108). It appears that the virus is required to infect and replicate in the cells in order to induce the chemokine expression $(88,100,108)$. This mechanism of chemokine activation may be similar in RSV, rhinovirus and influenza virus.

\section{Chemokine and receptor targets in asthma}

The initial excitement of targeting chemokines during inflammation was fueled by the realization that these molecules mediated the localization and accumulation of leukocytes to a site of inflammation. In the early days of chemokine biology, when there were only a few chemokines identified, this prospect seemed straightforward: target IL-8 for neutrophilic infiltration and RANTES or MCP-1 for mononuclear infiltration. However, now there are between 45 and 50 different chemokines, which overlap in function and are differentially induced during various diseases. Therefore, targeting the correct or most important chemokine in a disease may not be feasible. Instead, the pharmaceutical industry has turned to attempting to inhibit chemokine function at the receptor level. The pharmacologics directed against G protein-coupled serpentine receptors have previously been successful. Data available from asthma patients and from models of allergic asthma suggest that there may be a number of viable chemokine receptor targets that will be prosperous (Table 2).

Perhaps the most sought after target has been CCR3. This receptor is highly expressed on eosinophils, and ligands that bind to CCR3, including eotaxin, MCP-3, MCP-4 and RANTES, are potent agonists that are expressed during asthma and mediate recruitment and accumulation of eosinophils at a site of inflammation (15). Reports have also identified CCR3 on subsets of Th2 lymphocytes derived in vitro. It is unclear whether this observation will hold in vivo; however, at least one report has shown that CCR3 is involved in Th2-cell accumulation during allergic responses in the lungs of mice (21). Other receptors have also been identified on Th2-type cells, including CCR4 and CCR8 $(76,82,83)$. The objective of targeting these latter two receptors will be to inhibit the recruitment of Th2 type cells to the airway and therefore block the long-term detrimental effects of the allergic responses. Interestingly, TCA3, a CCR8 ligand, can also directly induce smooth muscle cell contraction and, therefore, may be additionally attractive as a target (109). Yet another chemokine receptor target that appears to be promising is CCR2, which binds all of the MCP-1 family members. The data for justifying CCR2 as a target centers around its ability to recruit and activate basophils and mast cells (as discussed above), as well as its effects on lymphocyte recruitment and skewing towards Th2-lymphocyte maturation (30, 33, 34, 110-113). Whether targeting any of these receptors will make an impact on allergic asthmatic inflammation remains unclear and will need to be tested in viable preclinical models before reaching patient populations.

An aspect that will need to be explored for targeting these receptors over a long-term period is the effect on infectious responses of the lung. Will inhibiting a particular chemokine receptor pathway lead to increased susceptibility to infectious agents? Recent studies using receptor "knockout" animals would suggest that some of these responses may be affected in a detrimental way. Using a model of live Aspergillus-induced allergen responses in $\mathrm{CCR} 2^{-/-}$mice, the results suggest that these mice have a prolonged and more severe airway hyperreactive response (114) and also have a lack of clearance of the infectious organism from the airway. Since CCR2 appears to play an important role in mediating macrophage activation for increased pathogen phagocytosis and clearance, targeting this receptor may be very detrimental over a long-term period and allow the colonization of opportunistic organisms. Although relatively little is known about the function of other receptors, we do have some data on the role of the ligands that bind to those receptors. For example, MDC (a CCR4 ligand) also appears to mediate bacterial clearance and attenuate lethality in a bacterial sepsis model in mice (115). Targeting CCR4 with a pharmacologic may alter the host response to specific pathogens. These considerations must be taken into account and specifically tested as reagents for these receptors become available. 


\section{Conclusions}

Chemokines play an important part in asthmatic disease progression at multiple levels. The coordinated production of specific chemokines and the expression of a distinct subset of receptors likely dictate the intensity and severity of the asthmatic response. The exacerbation of asthmatic responses by viral infections may directly or indirectly induce multiple chemokines during viral replication in the resident cells of the lungs. Chemokines were originally described as mediators of leukocyte recruitment; however, recent evidence suggests that they can also influence the outcome of the immune response by altering the cytokine profile and by activating/degranulating multiple effector cell populations. In view of the diversity of chemokine production and the promiscuous binding pattern for multiple receptors, it is unlikely that a single chemokine or chemokine receptor-induced mechanism will be identified for therapy, but rather a multimechanistic approach may be the most promising. Only after determining the function of specific chemokine and chemokine receptors during different disease phases can their true functions be identified and specific molecules targeted.

\section{References}

1. Cyster JG. Leukocyte migration: scent of the $\mathrm{T}$ zone. Curr Biol 2000;10:R30-33.

2. Homey B, Zlotnik A. Chemokines in allergy. Curr Opin Immunol 1999;11:626-634.

3. Cyster JG. Chemokines and cell migration in secondary lymphoid organs. Science 1999;286:2098-2102.

4. Proost P, Wuyts A, van Damme J. The role of chemokines in inflammation. Int J Clin Lab Res 1996;26:211-223.

5. Taub DD. Chemokine-leukocyte interactions. The voodoo that they do so well. Cytokine Growth Factor Rev 1996;7:355-376.

6. Berkman $\mathrm{N}$, et al. Expression of RANTES mRNA and protein in airways of patients with mild asthma.

Am J Respir Crit Care Med 1996;154:1804-1811.

7. Lamkhioued B, et al. Increased expression of eotaxin in bronchoalveolar lavage and airways of asthmatics contributes to the chemotaxis of eosinophils to the site of inflammation. J Immunol 1997;159:4593-4601.

8. Holgate ST, Bodey KS, Janezic A, Frew AJ, Kaplan AP, Teran LM. Release of RANTES, MIP- $1 \alpha$, and MCP-1 into asthmatic airways following endobronchial allergen challenge. Am J Respir Crit Care Med 1997;156:1377-1383

9. Folkard SG, Westwick J, Millar AB. Production of interleukin-8, RANTES and MCP-1 in intrinsic and extrinsic asthmatics. Eur Respir J 1997;10:2097-2104.
10. Jahnz-Rozyk KM, Kuna P, Pirozynska E. Monocyte chemotactic and activating factor/monocyte chemoattractant protein (MCAF/MCP-1) in bronchoalveolar lavage fluid from patients with atopic asthma and chronic bronchitis.

J Investig Allergol Clin Immunol 1997;7:254-259.

11. Nocker RE, Out TA, Weller FR, Mul EP, Jansen HM, van der Zee JS. Influx of neutrophils into the airway lumen at $4 \mathrm{~h}$ after segmental allergen challenge in asthma. Int Arch Allergy Immunol 1999;1 19:45-53.

12. Erger RA, Casale TB. Interleukin- 8 is a potent mediator of eosinophil chemotaxis through endothelium and epithelium. Am J Physiol 1995;268:L1 17-L122.

13. Combadiere C, Ahuja SK, Van Damme J, Tiffany HL, Gao JL, Murphy PM. Monocyte chemoattractant protein-3 is a functional ligand for $\mathrm{CC}$ chemokine receptors 1 and $2 \mathrm{~B}$. J Biol Chem 1995;270:29671-29675.

14. Godiska R, Chantry D, Raport CJ, Schweickart VL, Trong HL, Gray PW. Monocyte chemotactic protein-4: tissuespecific expression and signaling through CC chemokine receptor-2.

J Leukoc Biol 1997;61:353-360.

15. Ying $\mathrm{S}$, et al. Eosinophil chemotactic chemokines (eotaxin, eotaxin-2, RANTES, monocyte chemoattractant protein-3 (MCP-3), and MCP-4), and C-C chemokine receptor 3 expression in bronchial biopsies from atopic and nonatopic (intrinsic) asthmatics.

J Immunol 1999;163:6321-6329.

16. Beck LA, et al. Cutaneous injection of RANTES causes eosinophil recruitment: comparison of nonallergic and allergic human subjects.

J Immunol 1997;159:2962-2972.
17. Taha RA, et al. Eotaxin and monocyte chemotactic protein-4 mRNA expression in small airways of asthmatic and nonasthmatic individuals. J Allergy Clin Immunol 1999;103:476-483.

18. Lilly CM, et al. Expression of eotaxin by human lung epithelial cells: induction by cytokines and inhibition by glucocorticoids. J Clin Invest 1997;99:1767-1773.

19. Yamada $H$, et al. Eotaxin is a potent chemotaxin for human basophils. Biochem Biophys Res Commun 1997;231:365-368

20. Ochensberger B, Tassera L, Bifrare D, Rihs S Dahinden CA. Regulation of cytokine expression and leukotriene formation in human basophils by growth factors, chemokines and chemotactic agonists. Eur J Immunol 1999;29:11-22.

21. Sallusto F, Lenig D, Mackay CR, Lanzavecchia A. Flexible programs of chemokine receptor expression on human polarized T helper 1 and 2 lymphocytes. J Exp Med 1998;187:875-883.

22. Wasserman SI. Mast cells and airway inflammation in asthma. Am J Respir Crit Care Med 1994;150:S39-S41.

23. Bates DV. Observations on asthma. Environ Health Perspect 1995;103:243-247.

24. De Pater-Huijsen FL, Pompen M, Jansen HM, Out TA. Products from mast cells influence T lymphocyte proliferation and cytokine production - relevant to allergic asthma? Immunol Lett 1997;57:47-51. 
25. Alam R, et al. Monocyte chemotactic protein2 , monocyte chemotactic protein-3, and fibroblast-induced cytokine. Three new chemokines induce chemotaxis and activation of basophils. J Immunol 1994;153:3155-3159.

26. Trautmann A, Toksoy A, Engelhardt E, Brocker EB, Gillitzer R. Mast cell involvement in normal human skin wound healing: expression of monocyte chemoattractant protein-1 is correlated with recruitment of mast cells which synthesize interleukin-4 in vivo.

J Pathol 2000;190:100-106.

27. Nilsson G, Mikovits JA, Metcalfe DD, Taub DD. Mast cell migratory response to interleukin-8 is mediated through interaction with chemokine receptor CXCR2/interleukin8RB.

Blood 1999;93:2791-2797.

28. Conti P, et al. Monocyte chemotactic protein1 is a proinflammatory chemokine in rat skin injection sites and chemoattracts basophilic granular cells. Int Immunol 1997;9:1563-1570.

29. Gonzalo JA, et al. The coordinated action of $\mathrm{CC}$ chemokines in the lung orchestrates allergic inflammation and airway hyperresponsiveness. J Exp Med 1998;188:157-167.

30. Campbell EM, et al. Monocyte chemoattractant protein-1 mediates cockroach allergen-induced bronchial hyperreactivity in normal but not $\mathrm{CCR} 2^{-/-}$ mice: the role of mast cells. J Immunol 1999;163:2160-2167.

31. Sousa AR, Lane SJ, Nakhosteen JA, Yoshimura T, Lee TH, Poston RN. Increased expression of the monocyte chemoattractant protein-1 in bronchial tissue from asthmatic subjects.

Am J Respir Cell Mol Biol 1994;1 0:142-147.

32. Devouassoux G, Metcalfe DD, Prussin C. Eotaxin potentiates antigen-dependent basophil IL-4 production. J Immunol 1999;163:2877-2882.

33. Conti $\mathrm{P}$, et al. Monocyte chemotactic protein1 provokes mast cell aggregation and $\left[{ }^{3} \mathrm{H}\right] 5 \mathrm{HT}$ release. Immunology 1995;86:434-440.

34. Conti P, et al. Impact of RANTES and MCP-1 chemokines on in vivo basophilic cell recruitment in rat skin injection model and their role in modifying the protein and mRNA levels for histidine decarboxylase. Blood 1997;89:4120-4127.

35. Bischoff SC, Krieger M, Brunner T, Dahinden CA. Monocyte chemotactic protein 1 is a potent activator of human basophils. J Exp Med 1992;175:1271-1275.
36. Lukacs NW, Lamm WJ, Strieter RM, Albert RK. Airway hyperreactivity is associated with specific leukocyte subset infiltration in a mouse model of allergic airway inflammation.

Pathobiology 1996;64:308-313.

37. Jung KS, Park HS. Evidence for neutrophil activation in occupational asthma. Respirology 1999;4:303-306.

38. Kay AB, Corrigan CJ. Asthma. Eosinophils and neutrophils.

Br Med Bull 1992;48:51-64.

39. Williams TJ, Das A, von Uexkull C, Nourshargh S. Neutrophils in asthma. Ann N Y Acad Sci 1991;629:73-81.

40. Lukacs NW, Ward PA. Inflammatory mediators, cytokines, and adhesion molecules in pulmonary inflammation and injury. Adv Immunol 1996;62:257-304.

41. Teran LM, et al. Leukocyte recruitment after local endobronchial allergen challenge in asthma. Relationship to procedure and to airway interleukin-8 release. Am J Respir Crit Care Med 1996;154:469-476.

42. Carroll N, Carello S, Cooke C, James A. Airway structure and inflammatory cells in fatal attacks of asthma. Eur Respir J 1996;9:709-715.

43. Sur S, et al. Sudden-onset fatal asthma. A distinct entity with few eosinophils and relatively more neutrophils in the airway submucosa? Am Rev Respir Dis 1993;148:713-719.

44. Lamblin C, et al. Bronchial neutrophilia in patients with noninfectious status asthmaticus.

Am J Respir Crit Care Med 1998;157:394-402.

45. Hallahan AR, Armour CL, Black JL. Products of neutrophils and eosinophils increase the responsiveness of human isolated bronchial tissue.

Eur Respir J 1990;3:554-558.

46. Haraguchi M, Shimura S, Shirato K. Morphometric analysis of bronchial cartilage in chronic obstructive pulmonary disease and bronchial asthma.

Am J Respir Crit Care Med 1999;159:1005-1013.

47. Driscoll KE, Simpson L, Carter J, Hassenbein D, Leikauf GD. Ozone inhalation stimulates expression of a neutrophil chemotactic protein, macrophage inflammatory protein 2 . Toxicol Appl Pharmacol 1993;119:306-309.

48. Vagaggini B, et al. Airway inflammatory response to ozone in subjects with different asthma severity.

Eur Respir J 1999;13:274-280.
49. Holz O, et al. Ozone-induced airway inflammatory changes differ between individuals and are reproducible. Am J Respir Crit Care Med 1999;159:776-784.

50. Hiltermann TJ, et al. Effect of ozone exposure on maximal airway narrowing in nonasthmatic and asthmatic subjects. Clin Sci (Colch) 1995;89:619-624.

51. Basha MA, Gross KB, Gwizdala CJ, Haidar AH, Popovich J Jr. Bronchoalveolar lavage neutrophilia in asthmatic and healthy volunteers after controlled exposure to ozone and filtered purified air. Chest 1994;106:1757-1765.

52. Lukacs NW, et al. Mast cells produce ENA-78, which can function as a potent neutrophil chemoattractant during allergic airway inflammation. J Leukoc Biol 1998;63:746-751.

53. Xiu Q, et al. Bronchial hyperresponsiveness and airway neutrophil accumulation induced by interleukin- 8 and the effect of the thromboxane A2 antagonist S-1452 in guinea-pigs. Clin Exp Allergy 1995;25:51-59.

54. Kay AB, Barata L, Meng Q, Durham SR, Ying S. Eosinophils and eosinophil-associated cytokines in allergic inflammation. Int Arch Allergy Immunol 1997;113:196-199.

55. Corrigan CJ, Kay AB. T cells and eosinophils in the pathogenesis of asthma. Immunol Today 1992;13:501-507.

56. Kitayama J, Mackay CR, Ponath PD, Springer TA. The $\mathrm{C}-\mathrm{C}$ chemokine receptor CCR3 participates in stimulation of eosinophil arrest on inflammatory endothelium in shear flow. J Clin Invest 1998;101:2017-2024.

57. Ying $\mathrm{S}$, et al. Enhanced expression of eotaxin and CCR3 mRNA and protein in atopic asthma. Association with airway hyperresponsiveness and predominant colocalization of eotaxin mRNA to bronchial epithelial and endothelial cells Eur J Immunol 1997;27:3507-3516.

58. Polentarutti N, Introna M, Sozzani S, Mancinelli R, Mantovani G, Mantovani A. Expression of monocyte chemotactic protein3 in human monocytes and endothelial cells. Eur Cytokine Netw 1997;8:271-4.

59. Stellato C, et al. Production of the novel C-C chemokine MCP-4 by airway cells and comparison of its biological activity to other C-C chemokines. J Clin Invest 1997;99:926-936. 
60. Forssmann U, et al. Eotaxin-2, a novel CC chemokine that is selective for the chemokine receptor CCR3, and acts like eotaxin on human eosinophil and basophil leukocytes. J Exp Med 1997;185:2171-2176.

61. Rot A, Krieger M, Brunner T, Bischoff SC, Schall TJ, Dahinden CA. RANTES and macrophage inflammatory protein $1 \alpha$ induce the migration and activation of normal human eosinophil granulocytes. J Exp Med 1992;176:1489-1495.

62. Lukacs NW, Strieter RM, Shaklee CL, Chensue SW, Kunkel SL. Macrophage inflammatory protein- $1 \alpha$ influences eosinophil recruitment in antigen-specific airway inflammation. Eur J Immunol 1995;25:245-251.

63. Lukacs NW, Standiford TJ, Chensue SW, Kunkel RG, Strieter RM, Kunkel SL. C-C chemokine-induced eosinophil chemotaxis during allergic airway inflammation. J Leukoc Biol 1996;60:573-578.

64. Post TW, Bozic CR, Rothenberg ME, Luster AD, Gerard N, Gerard C. Molecular characterization of two murine eosinophil $\beta$-chemokine receptors. J Immunol 1995;155:5299-5305.

65. Gonzalo JA, et al. Mouse monocyte-derived chemokine is involved in airway hyperreactivity and lung inflammation. J Immunol 1999;163:403-411.

66. Bochner BS, et al. Macrophage-derived chemokine induces human eosinophil chemotaxis in a CC chemokine receptor 3and $\mathrm{CC}$ chemokine receptor 4 -independent manner.

J Allergy Clin Immunol 1999;103:527-532.

67. Kunkel SL. Th1- and Th2-type cytokines regulate chemokine expression. Biol Signals 1996;5:197-202.

68. Teran LM, et al. Th1- and Th2-type cytokines regulate the expression and production of eotaxin and RANTES by human lung fibroblasts. Am J Respir Cell Mol Biol 1999;20:777-786.

69. Sauty AM, et al. 1999. The T cell-specific CXC chemokines IP-10, Mig, and I-TAC are expressed by activated human bronchial epithelial cells.

J Immunol 1999;162:3549-3558.

70. Schrum S, Probst P, Fleischer B, Zipfel PF. Synthesis of the CC-chemokines MIP- $\alpha$, MIP- $\beta$, and RANTES is associated with a type 1 immune response.

J Immunol 1996;157:3598-3604.

71. Bonecchi R, et al. Differential expression of chemokine receptors and chemotactic responsiveness of type $1 \mathrm{~T}$ helper cells (Th1s) and Th2s.

J Exp Med 1998;187:129-134.
72. Sallusto F, et al. 1999. Switch in chemokine receptor expression upon TCR stimulation reveals novel homing potential for recently activated T cells.

Eur J Immunol 1999;29:2037-2045.

73. Mochizuki M, Bartels J, Mallet AI, Christophers E, Schroder JM. IL-4 induces eotaxin: a possible mechanism of selective eosinophil recruitment in helminth infection and atopy.

J Immunol 1998;160:60-68.

74. Stellato C, et al. Differential regulation of epithelial-derived $\mathrm{C}$-C chemokine expression by IL-4 and the glucocorticoid budesonide. J Immunol 1999;163:5624-5632.

75. Galli G, et al. Macrophage-derived chemokine production by activated human $\mathrm{T}$ cells in vitro and in vivo: preferential association with the production of type 2 cytokines. Eur J Immunol 2000;30:204-210.

76. Andrew DP, et al. STCP-1 (MDC) CC chemokine acts specifically on chronically activated Th2 lymphocytes and is produced by monocytes on stimulation with Th2 cytokines IL-4 and IL-13. J Immunol 1998;161,:5027-5038.

77. Zlotnik A, Morales J, Hedrick JA. Recent advances in chemokines and chemokine receptors.

Crit Rev Immunol 1999;19:1-47.

78. Campbell EM, Kunkel SL, Strieter RM, Lukacs NW. Temporal role of chemokines in a murine model of cockroach allergen-induced airway hyperreactivity and eosinophilia. J Immunol 1998;161:7047-7053.

79. Lukacs NW, Strieter RM, Warmington K, Lincoln P, Chensue SW, Kunkel SL. Differential recruitment of leukocyte populations and alteration of airway hyperreactivity by C-C family chemokines in allergic airway inflammation.

J Immunol 1997;1 58:4398-4404.

80. Gonzalo JA, et al. Eosinophil recruitment to the lung in a murine model of allergic inflammation. The role of $\mathrm{T}$ cells, chemokines, and adhesion receptors. J Clin Invest 1996;98:2332-2345.

81. Lukacs NW, Oliveira SH, Hogaboam CM. Chemokines and asthma: redundancy of function or a coordinated effort? J Clin Invest 1999;104:995-999.

82. Zingoni A, et al. The chemokine receptor CCR8 is preferentially expressed in Th2 but not Th1 cells.

J Immunol 1998;161:547-551.

83. Lloyd CM, et al. CC chemokine receptor (CCR) 3 /eotaxin is followed by CCR4/monocyte-derived chemokine in mediating pulmonary $\mathrm{T}$ helper lymphocyte type 2 recruitment after serial antigen challenge in vivo. J Exp Med 2000;191:265-274

84. Davies RJ, Devalia JL. Asthma. Epithelial cells. Br Med Bull 1992;48:85-96.
85. Polito AJ, Proud D. Epithelial cells as regulators of airway inflammation. J Allergy Clin Immunol 1998;102:714-718.

86. Folkerts G, Nijkamp FP. 1998. Airway epithelium: more than just a barrier! Trends Pharmacol Sci 1998;19:334-341.

87. Erjefalt JS, Sundler F, Persson CG. Epithelial barrier formation by airway basal cells. Thorax 1997;52:213-217.

88. Olszewska-Pazdrak B, et al. Cell-specific expression of RANTES, MCP-1, and MIP- $\alpha$ by lower airway epithelial cells and eosinophils infected with respiratory syncytial virus. J Virol 1998;72:4756-4764.

89. Li L, et al. Effects of Th2 cytokines on chemokine expression in the lung: IL-13 potently induces eotaxin expression by airway epithelial cells. J Immunol 1999;162:2477-2487.

90. Ray P, Yang L, Zhang DH, Ghosh SK, Ray A. Selective up-regulation of cytokine-induced RANTES gene expression in lung epithelial cells by overexpression of IкBR. J Biol Chem 1997;272:20191-20197.

91. Bonfield TL, Konstan MW, Burfeind P, Panuska JR, Hilliard JB, Berger M. Normal bronchial epithelial cells constitutively produce the anti-inflammatory cytokine interleukin-10, which is downregulated in cystic fibrosis. Am J Respir Cell Mol Biol 1995;13:257-261.

92. Li D, et al. Eotaxin protein and gene expression in guinea-pig lungs: constitutive expression and upregulation after allergen challenge. Eur Respir J 1997;10:1946-1954.

93. Bonecchi R, et al. Up-regulation of CCR 1 and CCR3 and induction of chemotaxis to CC chemokines by IFN- $\gamma$ in human neutrophils. J Immunol 1999;162:474-479.

94. Busse WW, Gern JE, Dick EC. The role of respiratory viruses in asthma. Ciba Found Symp 1997;206:208-219.

95. Eigen $\mathrm{H}$. The RSV-asthma link: the emerging story. Introduction. J Pediatr 1999;135:1

96. Welliver RC. RSV and chronic asthma. Lancet 1995;346:789-790.

97. Hogg JC. Childhood viral infection and the pathogenesis of asthma and chronic obstructive lung disease. Am J Respir Crit Care Med 1999;160:26-28.

98. Grunberg K, et al. Effect of experimental rhinovirus 16 colds on airway hyperresponsiveness to histamine and interleukin8 in nasal lavage in asthmatic subjects in vivo. Clin Exp Allergy 1997;27:36-45.

99. Grunberg K, Sterk PJ. Rhinovirus infections: induction and modulation of airways inflammation in asthma. Clin Exp Allergy 1999;29:65-73 
100. Becker S, Reed W, Henderson FW, Noah TL. RSV infection of human airway epithelial cells causes production of the $\beta$-chemokine RANTES.

Am J Physiol 1997;272:512-520.

101. Matsukawa A, Lukacs NW, Standiford TJ, Chensue SW, Kunkel SL. Adenoviral-mediated overexpression of monocyte chemoattractant protein-1 differentially alters the development of Th1 and Th2 type responses in vivo.

J Immunol 1999;4:1699-16704.

102. Abu-Harb M, et al. IL-8 and neutrophil elastase levels in the respiratory tract of infants with RSV bronchiolitis. Eur Respir J 1999;14:139-143.

103. Harrison AM, Bonville CA, Rosenberg HF, Domachowske JB. Respiratory syncytical virus-induced chemokine expression in the lower airways: eosinophil recruitment and degranulation.

Am J Respir Crit Care Med

1999;159:1918-1924.

104. Alam R, et al. RANTES is a chemotactic and activating factor for human eosinophils. J Immunol 1993;150:3442-3451.
105. Kameyoshi Y, Dorschner A, Mallet AI, Christophers E, Schroder J-M. Cytokine RANTES released by thrombin-stimulated platelets is a potent attractant for human eosinophils.

J Exp Med 1992;1 176:587-594.

106. Umetsu DT, DeKruyff RH. Th1 and Th2 CD4 cells in the pathogenesis of allergic diseases. Proc Soc Exp Biol Med 1997;215:11-20.

107. Hansen G, Berry G, DeKruyff RH, Umetsu DT. Allergen-specific Th1 cells fail to counterbalance Th2 cell-induced airway hyperreactivity but cause severe airway inflammation.

J Clin Invest 1999;103:175-183.

108. Roebuck KA, Carpenter LR, Lakshminarayanan V, Page SM, Moy JN, Thomas LL. Stimulus-specific regulation of chemokine expression involves differential activation of the redox-responsive transcription factors AP-1 and NF- $\mathrm{kB}$. J Leukoc Biol 1999;65:291-298.

109. Luo Y, D’Amore PA, Dorf ME. $\beta$-chemokine TCA3 binds to and activates rat vascular smooth muscle cells. J Immunol 1996;157:2143-2148.

110. Warmington KS, et al. Effect of C-C chemokine receptor 2 (CCR2) knockout on type-2 (schistosomal antigen-elicited) pulmonary granuloma formation: analysis of cellular recruitment and cytokine responses. Am J Pathol 1999;154:1407-1416.
111. Lukacs NW, et al. C-C chemokines differentially alter interleukin-4 production from lymphocytes. Am J Pathol 1997;150:1861-1868.

112. Hogaboam CM, Lukacs NW, Chensue SW, StrieterRM, Kunkel SL. Monocyte chemoattractant protein- 1 synthesis by murine lung fibroblasts modulates $\mathrm{CD} 4^{+}$ T cell activation. J Immunol 1998;160:4606-4614.

113. Karpus WJ, Lukacs NW, Kennedy KJ, Smith WS, Hurst SD, Barrett TA. Differential CC chemokine-induced enhancement of $\mathrm{T}$ helper cell cytokine production. J Immunol 1997;158:4129-4136.

114. Matsukawa A, Hogaboam CM, Lukacs NW, LincolnPM, Strieter RM, Kunkel SL. Endogenous MCP-1 influences systemic cytokine balance in a murine model of acute septic peritonitis. Exp Mol Pathol 2000;68:77-84.

115. Blease K, et al. Enhanced pulmonary allergic responses to Aspergillus in CCR2 ${ }^{-/-}$mice. J Immunol (In press). 